\title{
Mesoscale simulations of organized convection: Importance of convective equilibrium
}

\author{
By J. M. DONE*1, G. C. CRAIG ${ }^{2}$, S. L. GRAY ${ }^{1}$, P. A. CLARK ${ }^{3}$ and M. E. B. GRAY ${ }^{4}$ \\ ${ }^{1}$ University of Reading, $U K$ \\ ${ }^{2}$ Deutsches Zentrum für Luft- und Raumfahrt, Oberpfaffenhofen, Germany \\ ${ }^{3}$ Met Office Joint Centre for Mesoscale Meteorology, University of Reading, UK \\ ${ }^{4}$ Met Office, Exeter, $U K$
}

(Received 1 June 2004; revised 13 August 2005)

\section{SUMMARY}

The validity of convective parametrization breaks down at the resolution of mesoscale models, and the success of parametrized versus explicit treatments of convection is likely to depend on the large-scale environment. In this paper we examine the hypothesis that a key feature determining the sensitivity to the environment is whether the forcing of convection is sufficiently homogeneous and slowly varying that the convection can be considered to be in equilibrium. Two case studies of mesoscale convective systems over the UK, one where equilibrium conditions are expected and one where equilibrium is unlikely, are simulated using a mesoscale forecasting model. The time evolution of area-average convective available potential energy and the time evolution and magnitude of the timescale of convective adjustment are consistent with the hypothesis of equilibrium for case 1 and nonequilibrium for case 2 .

For each case, three experiments are performed with different partitionings between parametrized and explicit convection: fully parametrized convection, fully explicit convection and a simulation with significant amounts of both. In the equilibrium case, bulk properties of the convection such as area-integrated rain rates are insensitive to the treatment of convection. However, the detailed structure of the precipitation field changes; the simulation with parametrized convection behaves well and produces a smooth field that follows the forcing region, and the simulation with explicit convection has a small number of localized intense regions of precipitation that track with the mid-level flow. For the non-equilibrium case, bulk properties of the convection such as area-integrated rain rates are sensitive to the treatment of convection. The simulation with explicit convection behaves similarly to the equilibrium case with a few localized precipitation regions. In contrast, the cumulus parametrization fails dramatically and develops intense propagating bows of precipitation that were not observed. The simulations with both parametrized and explicit convection follow the pattern seen in the other experiments, with a transition over the duration of the run from parametrized to explicit precipitation. The impact of convection on the large-scale flow, as measured by upper-level wind and potential-vorticity perturbations, is very sensitive to the partitioning of convection for both cases.

KEYWORDS: Convective parametrization Explicit convection Precipitation

\section{INTRODUCTION}

\section{(a) Parametrized and explicit convection}

Mesoscale models are capable of providing useful information for quantitative precipitation forecasting (QPF), but are restricted by the computational limits of operational forecasting. The compromise is particularly challenging under convectively unstable conditions (e.g. Stensrud et al. 2000; Stensrud 2001) because the range of scales of convective motions in nature, from microscale turbulence to organized convective circulations, overlaps with the grid scales of current mesoscale models $(4-30 \mathrm{~km})$. In a summary of cumulus parametrization in mesoscale models, Kuo et al. (1997) recognized that, even though the theory of parametrization breaks down (i.e. the grid box is not large enough to average over many convective clouds) parametrization is still necessary to remove instability on subgrid scales. Similarly, Zhang et al. (1988) and Kain and Fritsch (1998) showed that a convection scheme is important to prevent unrealistic growth on the smallest resolvable scales of the model. But, while it may be necessary

* Corresponding author's present address: National Center for Atmospheric Research, PO Box 3000, Boulder, CO 80307, USA. e-mail: done@ucar.edu

(C) Royal Meteorological Society, 2006. Contributions by P. A. Clark and M. E. B. Gray are Crown Copyright. 
to parametrize small-scale convection, it is likely that the larger-scale organized convective circulations will be represented explicitly to some extent. Most mesoscale models, therefore, include a parametrization of convection and an explicit scheme that represents condensation and precipitation associated with the resolved flow. Despite significant effort, the question still remains as to how the physical processes should be partitioned between parametrized and explicit components in a mesoscale model. This issue is further complicated by the propagation and upscale growth associated with mesoscale organization (e.g. Dudhia 1989; Kain and Fritsch 1998).

Errors involved in parametrizing convection may mean that an explicit treatment (without a parametrization of convection) is more useful in terms of precipitation location and intensity, even at resolutions that can resolve only the largest convective scales. However, such treatment aliases convection onto the smallest resolvable scale, leading to spurious delays in the onset and subsequent overprediction of convection (e.g. Zhang et al. 1988; Molinari and Dudek 1986, 1992; Kato and Saito 1995). Furthermore, a lack of timescale separation between convection and the large-scale forcing can result in the simultaneous occurrence of instability and explicit convection (Zhang et al. 1988).

In addition to the small-scale details of convection, the complex and highly nonlinear interaction between convection and the large scales introduces further difficulty for convective QPF. The feedback of convection on the large-scale flow is sensitive to the vertical heating and moistening profiles of convection (e.g. Kuo and Reed 1988). These profiles are significantly different between single convective cells and organized convective systems (Houze 1982; Johnson 1984). Accurate representation of the vertical profiles of organized convection may be important for the downstream flow and subsequent convection.

\section{(b) Dependence of convective behaviour on the large-scale flow}

In practice, the partitioning of precipitation between parametrized and explicit components is found to be case-sensitive (Gallus 1999). Zhang et al. (1988) hypothesized that the relative roles of parametrized versus explicit convection depend on the nature of the large-scale forcing for upward motion-quasi-stationary versus propagating and weak versus strong. Furthermore, the degree of sensitivity of convective behaviour to simulation features such as resolution, the convection scheme or small-scale details in the initial conditions is also highly case-dependent.

It is an interesting exercise to review some of the sensitivity studies on convection that have been published in recent years (Schwartz et al. 1990; Brandes 1990; Stensrud and Fritsch 1993, 1994; Wang and Seaman 1997; Spencer and Stensrud 1998; Stensrud et al. 1999; Gallus 1999; Liu et al. 2001). A qualitative impression can be formed of the dependence of overall properties of simulated convection (such as precipitation, heating and moistening) on certain features of the large-scale environments. The case studies for which the overall properties of the convective system were predictable were characterized by strong large-scale forcing for upward motion. For these cases, the region of convective available potential energy (CAPE) was collocated with approximately zero convective inhibition $(C I N)$. Under strong large-scale forcing, $C A P E$ is being continuously generated by the large scales and, in the absence of $C I N$, convection is free to act. It is reasonable to expect that, for these cases, the rate of stabilization of the atmosphere by convection is able to balance the rate of destabilization by the large-scale forcing. The convection, thus, has the opportunity to reach an equilibrium where its mean properties are set by the environment. 
Conversely, case studies for which the net properties of the convective system were not predictable tended to be characterized by weak synoptic forcing. For these cases, the region of $C A P E$ was collocated with $C I N$. Under weak large-scale forcing, CAPE and $C I N$ are strongly modulated by mesoscale details such as boundary-layer convergence lines and cold pools. Moreover, this mesoscale structure is often generated by the convection itself (e.g. cold pools). In such cases, there may be little opportunity for convection to come into balance with the large-scale forcing, and convective equilibrium may not be satisfied. The expected result is a large sensitivity to any details of the simulation that might affect convective inhibition or triggering, and poor performance of cumulus parametrization schemes.

\section{(c) Equilibrium and non-equilibrium convection}

The contrast between equilibrium and non-equilibrium (or 'triggered') convection has been discussed in detail by Emanuel (1994, Chapter 11.2), who contrasted circumstances in which the generation of CAPE by large-scale processes nearly balances its consumption by convection with situations in which large-scale processes build up $C A P E$ over a long timescale, followed by violent outbreak of convection. In the first case, the CAPE remains small, while in the second case it builds up over time, and then decreases after convection is initiated. A separation of timescales between the large-scale forcing and convective response is thus a necessary condition for convective equilibrium. The second necessary condition for equilibrium is a spatial scale separation where the environment is reasonably uniform over a region large enough to contain many convective elements. This condition is not necessarily satisfied in a mesoscale model that is able to resolve flow variations on scales of a few kilometres, but may be when the flow is dominated by scales larger than the model grid size. It is worth noting however that, in regions of strong forcing, the density of convective elements is higher, making it more likely that a spatial scale separation could exist (Craig and Cohen 2006; Cohen and Craig 2006).

Determining whether equilibrium exists in a particular situation is difficult. Arakawa and Schubert (1974), for example, looked for stationarity of the cloud work function $\mathcal{A}$. This quantity, a generalization of CAPE based on the buoyancy of a spectrum of entraining plumes, should vary slowly in comparison with its large-scale generation. This is not a definitive test, however, since $\mathcal{A}$ is an imperfect estimate of convective instability due to the limitations of the spectral entraining plume model, most significantly in the original 1974 paper, due to the omission of boundary-layer modification by convective downdraughts.

Although a definitive test may be out of reach, it is useful in the present paper to have at least a rough indicator of convective equilibrium. We consider the time evolution of $C A P E$, and form an estimate for the convective timescale, $\tau_{\mathrm{c}}$. This is estimated from the rate at which instability (measured by $C A P E$ ) is being removed by convective heating:

$$
\tau_{\mathrm{c}} \sim \frac{C A P E}{\mathrm{~d}(C A P E) / \mathrm{d} t}
$$

where $C A P E$ is defined as

$$
C A P E=\int \frac{g}{T_{0}}\left(T_{\mathrm{a}}-T\right) \mathrm{d} z,
$$

with $g$ the acceleration of gravity, $T$ the environmental temperature, $T_{\mathrm{a}}$ the temperature of a pseudo-adiabatically lifted boundary-layer parcel, and $T_{0}$ a constant reference 
temperature. The $C A P E$ can be removed by supplying enough heat to eliminate the difference between $T$ and $T_{\mathrm{a}}$ through the column. The actual vertically integrated latentheat release, and thus $\mathrm{d}(C A P E) / \mathrm{d} t$, can be determined from the precipitation rate $P$ $\left(\mathrm{kg} \mathrm{s}^{-1}\right)$

$$
L_{\mathrm{v}} P=\iint \rho C_{p} \frac{\mathrm{d} T}{\mathrm{~d} t} \mathrm{~d} z \mathrm{~d} A=\frac{\rho C_{p} T_{0}}{g} \frac{\mathrm{d}(A C A P E)}{\mathrm{d} t},
$$

where $A C A P E$ is the integral of $C A P E$ over the convective region of area $A$ (units $\left.\mathrm{J} \mathrm{kg}-1 \mathrm{~m}^{2}\right), L_{\mathrm{v}}$ is the latent heat of vaporization, $\rho$ is the air density and $C_{p}$ the specific heat at constant pressure. This calculation ignores convective modification of the boundary layer, and will thus overestimate the convective timescale significantly, but should nonetheless help to distinguish between potential equilibrium and nonequilibrium convection. A typical synoptic timescale is usually taken to be a day or more, but over land the changes in forcing associated with the diurnal cycle are likely to be important and it is probably more appropriate to consider a timescale of six hours or so. If our estimated convective timescale $\tau_{\mathrm{c}}$ is less than this, then it is an indication of equilibrium convection, while longer timescales would suggest nonequilibrium conditions.

\section{(d) Aims of this study}

This paper explores the hypothesis that the behaviour of explicit and parametrized convection is closely coupled to whether or not the convection is in equilibrium with the large-scale forcing. In particular, we consider two cases of mesoscale convective systems (MCSs) over the UK-one where distributions of CAPE and CIN indicate that equilibrium is possible and one where equilibrium is unlikely - in a set of experiments designed to vary the partitioning of convection between explicit and parametrized components. We pose the following questions:

- Does a cumulus parametrization behave well when equilibrium is expected, even though model resolution is too high for a large amount of convection within a single grid box?

- Does explicitly resolved convection also behave well when equilibrium is expected, although model resolution is too coarse to resolve individual convective cells?

- Does either treatment of convection provide useful information when equilibrium is not expected, given model resolution that is inappropriate for both?

In considering these questions we examine the location, horizontal scale, intensity, and propagation of the simulated precipitation, and evaluate the generation of potential vorticity (PV) as a measure of the convective feedback on the larger-scale atmospheric flow.

In section 2, an overview of the two case studies of organized convection is provided using observational and model data. An outline of the mesoscale version of the Met Office unified model used in this study is given in section 3, along with a description of experimental set-up. Section 4 considers the evidence of equilibrium or non-equilibrium in the two cases, and describes the behaviour of the area-integrated precipitation in the different experiments. Section 5 describes the small-scale structure of the convection, and section 6 considers the feedback on the larger scales. Finally, conclusions are presented in section 7 . 

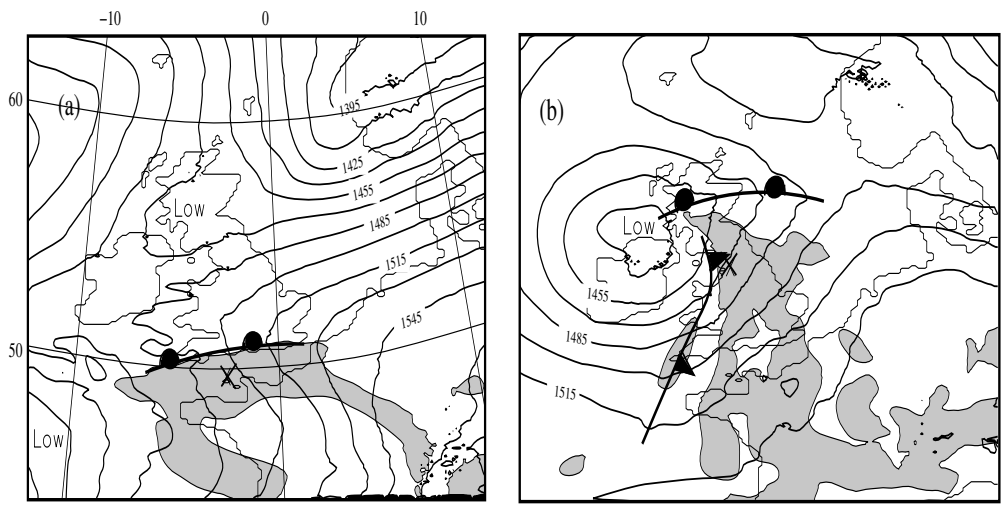

Figure 1. Model geopotential height at $850 \mathrm{mb}$ (using a contour interval of $15 \mathrm{~m}$ ) and $\theta_{\mathrm{w}}>289 \mathrm{~K}$ (shaded) at $850 \mathrm{mb}$ for (a) case 1 at 0600 UTC 29 May 1999, and (b) case 2 at 1800 UTC 11 September 2000. The initial triggering locations of convection, as determined from Meteosat infrared imagery, are marked by a cross.

Warm and cold fronts at $850 \mathrm{mb}$ from the model are also shown.

\section{Two CASE STUDIES}

A brief summary of the synoptic environments and evolution of two MCSs is presented here using Meteosat infrared imagery and the large-scale model dynamics. The large-scale environment is well-represented by the model and in using the model analysis in this section we restrict attention to times before either model convection or observed convection impacts the large scales.

\section{(a) Case 1}

The meteorological situation known as the Spanish plume, described by Morris (1986), occurred during 28 and 29 May 1999 and provided favourable conditions for organized convection over the UK. A warm moist plume below $750 \mathrm{mb}$, shown in Fig. 1(a), tracked north beneath a cooler drier mid- and upper-level south-westerly flow. The front edge of the low-level plume became elevated above a low-level (below $850 \mathrm{mb}$ ) easterly flow resulting in a large-scale unstable region with significant vertical shear of the horizontal wind, as shown in Fig. 2(a). Convection in the real atmosphere was triggered on the elevated plume over the Bay of Biscay at 0000 UTC 29 May 1999. Further convection was triggered close to southern England between 0330 and 0400 UTC, shown in Fig. 2(a) at 0630 UTC. The triggering location in the real atmosphere, marked by a cross in Fig. 3(a), is within a region of high CAPE and outside a region of high $C I N^{*}$. This convection evolved into a coherent MCS over southern England, and tracked north-eastward with the mid-level environmental flow towards the North Sea during the day. Propagating parallel lines of convection developed on the south-eastern side of the mature MCS. The most easterly line re-intensified at 1400 UTC and propagated in a direction distinct from the mid-level flow at $11 \mathrm{~m} \mathrm{~s}^{-1}$ across southern England.

\footnotetext{
* CAPE and CIN are calculated off-line, based on pseudo-adiabatic parcel ascent. The values of CAPE and CIN are taken from the parcel ascent with the largest value of $(C A P E-C I N)$ on lifting from successive pressure levels $50 \mathrm{mb}$ apart. The buoyancy assumptions are different to those made by the parametrization scheme and the large-scale model equations, and the calculation omits potentially significant contributions to CAPE and CIN from unresolved scales. For these reasons, Figs. 3(a) and (b) are shown only to provide information on the general stability of the large-scale atmosphere.
} 

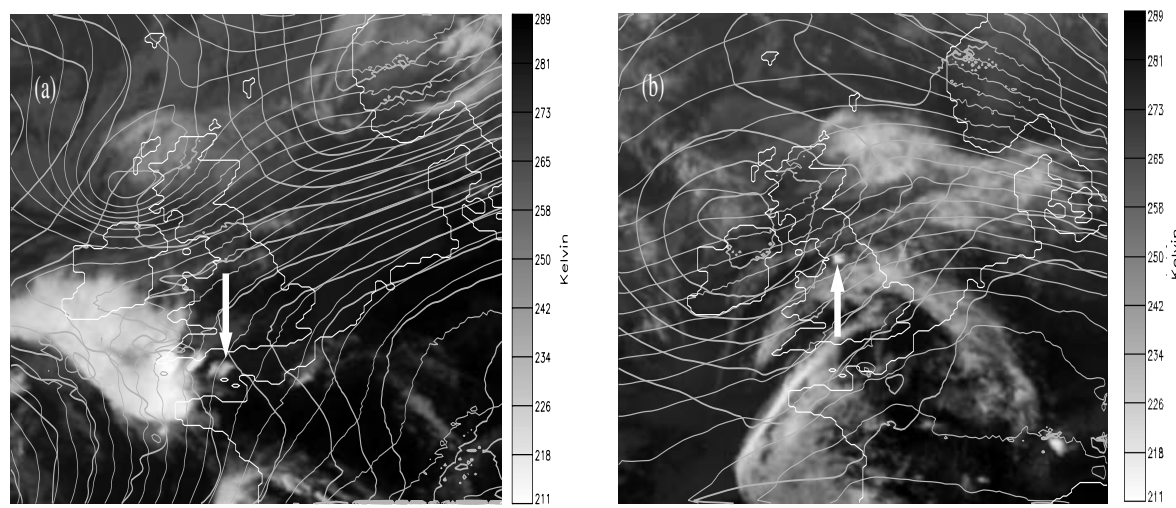

Figure 2. Meteosat infrared imagery after initial triggering for (a) case 1 at 0630 UTC 29 May 1999 showing convection over the English Channel, and (b) case 2 at 1830 UTC 11 September 2000 showing convection over north-west England. Also shown are the cloud cover and the $850 \mathrm{mb}$ (thick lines) and $500 \mathrm{mb}$ (thin lines) geopotential heights from the model (contour interval $15 \mathrm{~m}$ ).

A large part of the region of $C A P E$ was collocated with almost zero CIN. The absence of $C I N$ suggests that convection is free to respond to changes in $C A P E$, satisfying the necessary condition for convective equilibrium, although the appearance of the squall-line-like propagation late in the life of the system complicates the picture.

\section{(b) Case 2}

A synoptic-scale wave-cyclone below $600 \mathrm{mb}$ tracked over the UK on 11 September 2000, shown at 1800 UTC in Fig. 1(b). The low-level northward advection of warm moist air was overlain at $650 \mathrm{mb}$ by a north-eastward jet of cooler drier air. The veering of the horizontal wind together with a deep unstable layer provided favourable conditions for organized convection over north-west England. Convection was triggered in the real atmosphere between 1730 and 1800 UTC within the warm sector, close to the cold front of the cyclone, as indicated in Fig. 1(b). This first convective cell over northwest England is shown in Fig. 2(b) within the region of veering horizontal wind. Forced ascent due to flow along isentropic surfaces sloping backwards with height, associated with the eastward moving cold front, resulted in almost zero CIN close to the cold front. Figure 3(b) indicates the convection was triggered within this region of high $C A P E$ and almost zero CIN. The convection developed into a coherent MCS as it tracked northeastward over north-east England with the mid-level environmental flow.

In contrast to case 1 , most of the region of $C A P E$ was collocated with high $C I N$. In the presence of $C I N$, convection is not free to respond to changes in $C A P E$, making it improbable that convective equilibrium was achieved.

\section{MODEL DESCRIPTION AND EXPERIMENTAL DESIGN}

Simulations are conducted using the mesoscale version of the Met Office Unified Model version 4.5 (Cullen 1993) formulated around the hydrostatic primitive-equation set. Computations are on a rotated latitude-longitude grid allowing for a grid spacing of approximately $12.5 \mathrm{~km}$ over a mesoscale domain (the domain can be seen in Fig. 1(a)) of $146 \times 182$ grid points. Vertical resolution is on $38 \eta$ levels, where $\eta$ is terrain-following near the surface, follows pressure levels near the model top and has hybrid levels in the mid-troposphere. Resolution is highest in the boundary layer where vertical gradients 

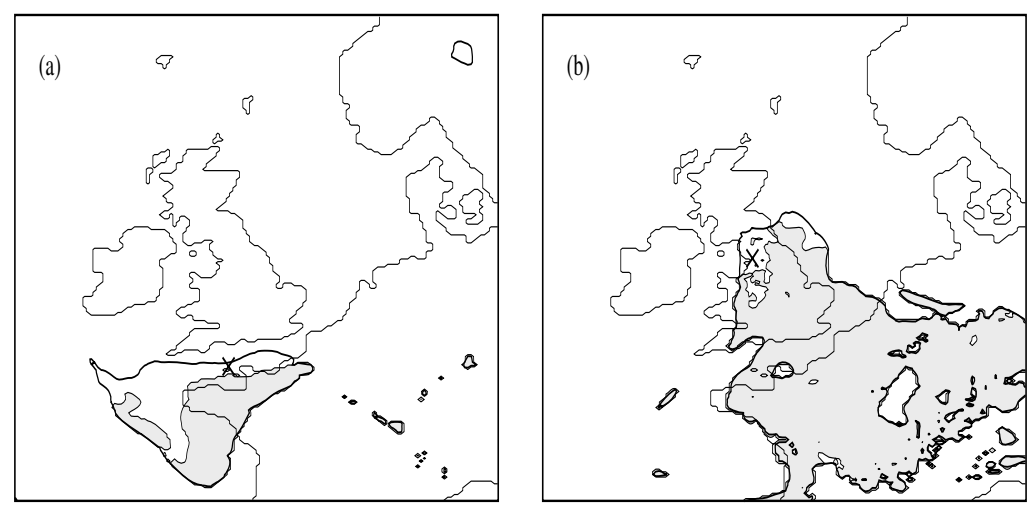

Figure 3. Model CAPE (enclosed by thick contour) and $C I N>10 \mathrm{~J} \mathrm{~kg}^{-1}$ within the contour of CAPE (shaded) prior to model convection initiation for (a) case 1 at 0400 UTC 29 May 1999 (CAPE $=300 \mathrm{~J} \mathrm{~kg}^{-1}$ contoured), and (b) case 2 at 1800 UTC 11 September $2000\left(C A P E=500 \mathrm{~J} \mathrm{~kg}^{-1}\right.$ contoured). The cross marks the triggering locations in the real atmosphere.

are expected to be large with 14 levels below about $800 \mathrm{mb}$. Model dynamics are solved using a split-explicit method using four advection steps per five-minute model time step.

\section{(a) Model physics}

The convective parametrization used in the Unified Model is a mass-flux scheme based on that of Gregory and Rowntree (1990), but with the buoyancy closure replaced by a $C A P E$ closure, in which cloud-base mass flux is calculated to be consistent with the removal of vertically integrated CAPE over a closure timescale, $\tau$. This closure is discussed in further detail in section 3(c). The scheme triggers if a parcel in the column, given a $0.2 \mathrm{~K}$ buoyancy excess, remains buoyant by $0.2 \mathrm{~K}$, or greater, in the next layer after ascent including entrainment. The scheme uses a one-dimensional cloud model based on a single entraining and detraining plume with coefficients chosen to represent an ensemble average of clouds with different mixing characteristics. An inverted plume represents downdraughts. Precipitation of condensed water is suppressed until the cloud exceeds a critical depth and cloud condensate threshold. Finally, net convective increments are added to grid-scale specific humidity and potential temperature.

Explicit cloud and precipitation processes are handled by a microphysically based mixed-phase transfer scheme (Wilson and Ballard 1999) representing water vapour, liquid water, rain and prognostic ice. Raindrop size obeys a Marshall and Palmer (1948) distribution, and fall speeds are from Sachidananda and Zrinć (1986). The long-wave and short-wave radiation scheme is based on the two-stream Edwards and Slingo (1996) code, and is called every hour. The boundary-layer scheme uses firstorder eddy diffusion with a top-of-mixed-layer entrainment scheme, and is non-local in unstable conditions (Lock et al. 2000). The surface exchange uses the Penman-Monteith formulation including four subsurface levels.

\section{(b) Initial and boundary conditions}

For case 1, the model is initialized at 1800 UTC 28 May 1999 from an ECMWF* analysis on a $1^{\circ}$ horizontal grid and 50 vertical levels interpolated onto the model grid. A Met Office mesoscale analysis was not available for this time. No additional data are assimilated. For case 2, the model is initialized from a Met Office mesoscale analysis.

\footnotetext{
* European Centre for Medium-Range Weather Forecasts.
} 
Data are assimilated using the 3DVAR approach (described by Lorenc et al. 2000), and the increments are added gradually over the period $\mathrm{T}-1$ to $\mathrm{T}+1$ hours, where $\mathrm{T}$ is the initial time: 0600 UTC 11 September 2000. For both cases, the start time is chosen such that convection was observed to initiate in the real atmosphere after a period of model spin-up (not shown). The model is forced by boundary conditions generated from the global version of the Unified Model updated every hour.

\section{(c) Control of partitioning between explicit and parametrized convection}

In order to understand the behaviour of parametrized and explicit convection, we wish to generate simulations where convective precipitation is fully parametrized, fully explicit, and where significant amounts of both occur. The closure timescale, $\tau$, in the Gregory and Rowntree (1990) scheme implicitly determines the partitioning between explicit and parametrized convection for a given environment. The physical processes that determine $\tau$ in the real atmosphere are not well known, and thus the choice of $\tau$ for mesoscale modelling is not clear. Simulations of the response of a convective ensemble suggest a timescale of an hour or so, and values of this order are typically employed in practice, although often chosen for pragmatic reasons.

Setting $\tau$ to be small (compared with the timescale for instability to develop on the grid) forces the majority of convection to be parametrized. Conversely, setting $\tau$ large (compared with the timescale for instability to develop on the grid) forces the majority of convection to be represented explicitly. A simulation with significant amounts of both parametrized and explicit convection is achieved by setting $\tau$ similar to the timescale for instability to develop on the grid. The first two outcomes are obtained by performing simulations for each case using $\tau=10 \mathrm{~min}$ (10MIN, hereafter) and $\tau=1$ day (1DAY, hereafter). Since it was observed that the default value of $\tau=2 \mathrm{~h}$ gave a mixture of convective and grid-scale convection, this was retained as a third simulation for each case (2HR, hereafter). Aspects of convection including location, timing, intensity and evolution are compared between the three experiments and observations. The magnitude and vertical structure of the large-scale modification is then compared between 10MIN, 1DAY and observations.

\section{RESUlTS I: EQUILIBRIUM AND PARTITIONING}

As a first step, the conjecture that case 1 represents equilibrium convection and case 2 non-equilibrium convection will be examined by considering the time evolution of both the area-average CAPE and the estimated timescale of convective adjustment, as computed from the $2 \mathrm{HR}$ simulation. The averaging areas are defined as static boxes that contain the region of $C A P E$ throughout the periods of interest. The averaging area is 11016 grid points for case 1, and 11284 grid points for case 2. Figure 4(a) shows that CAPE in case 1 remains relatively constant, with a modest value in the range 100 $150 \mathrm{~J} \mathrm{~kg}^{-1}$. The convective timescale (Fig. 4(b)), after an initial decrease in the first few hours of the simulation when the model precipitation was spinning up, has a value of about five hours. Given that this is an overestimate of the actual timescale (as noted in section 1(c)), this result, and the small and fairly constant value of CAPE, are consistent with the hypothesis of equilibrium convection.

In contrast, the $C A P E$ in case 2 increases steadily in the first part of simulation, then decreases rapidly through the afternoon, once convection breaks out (Fig. 4(a)). Correspondingly, the estimated convective adjustment timescale (Fig. 4(b)) is infinite before convection breaks out, and then decreases but remains long (many days). This pattern is consistent with the classical evolution of convection under the influence 
(a)

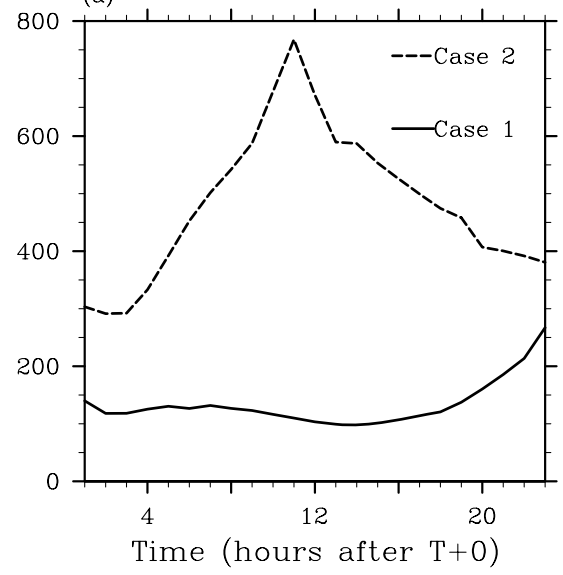

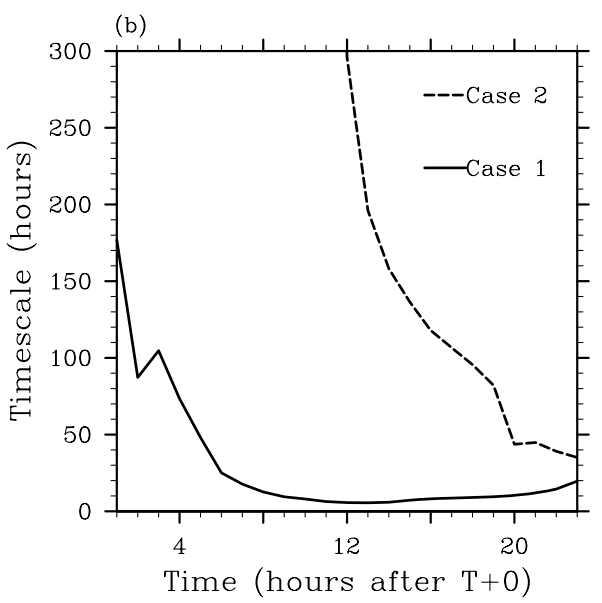

Figure 4. Time series of (a) area-average CAPE $\left(\mathrm{J} \mathrm{kg}^{-1}\right)$ and (b) convective timescale (hours) for cases 1 and 2. $\mathrm{T}+0$ corresponds to 1800 UTC 28 May 1999 for case 1 and 0600 UTC 11 September 2000 for case 2.

of the diurnal cycle, where instability builds up in the presence of a capping inversion, and then is suddenly released. This can certainly not be described as an equilibrium situation.

The ratios of parametrized-to-total hourly rain amount for the three experiments within the averaging areas, presented in Fig. 5, show the partitioning of convection* was highly sensitive to the closure timescale for both cases, as expected. The three experiments, therefore, provide three different representations of convection. The variation in partitioning with time is discussed further in section 5. Broadly similar partitioning occurred for both cases; however, it becomes difficult to interpret the partitioning for case 2 within the region of $C A P E$ as convection merged with the frontal zone after $\mathrm{T}+20$ (not shown).

Cumulative rainfall was only weakly sensitive to the partitioning of convection for case 1, as shown in Fig. 6(a). Most of the region of CAPE was collocated with low CIN (see Fig. 3(a)) and convection, either explicit or parametrized, was free to act. The result is that expected for an equilibrium situation, where precipitation corresponds directly to large-scale generation of $C A P E$. For case 2, the cumulative rainfall was sensitive to the partitioning of convection, as shown in Fig. 6(b). Most of the region of CAPE was collocated with high CIN (see Fig. 3(b)), and the occurrence of convection is dependent on how the parametrized or explicit processes are able to overcome that inhibition.

\section{RESULTS II: SMALL-SCALE SENSITIVITY TO PARTITIONING}

\section{(a) Simulations using a ten-minute closure timescale}

For case 1 experiment $10 \mathrm{MIN}$, the convective response to the large-scale destabilization was a region of parametrized precipitation with large-amplitude grid-scale noise, shown in Fig. 7(a), coincident with the region of CAPE and low CIN. The short adjustment timescale allowed parametrized convection to respond rapidly to the large scales, thus suppressing explicit convection almost entirely, as shown in Fig 5(a).

\footnotetext{
* Explicit rain rates associated with stable dynamical adjustment are small compared with the localized intense centres of explicit precipitation associated with convection, as shown later in section 5 . It is, therefore, assumed that the total explicit precipitation is equivalent to the total explicit convective precipitation to a good approximation over the potentially unstable regions.
} 

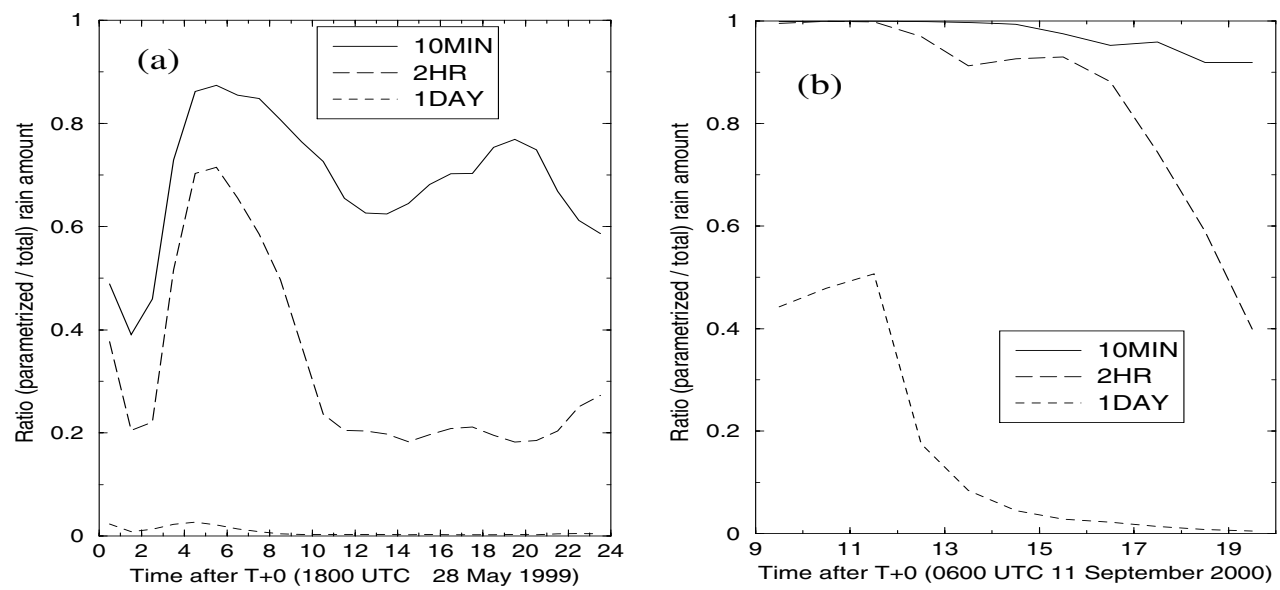

Figure 5. Ratio of parametrized-to-total hourly rain amount within the averaging areas for $10 \mathrm{MIN}, 2 \mathrm{HR}$ and 1DAY for (a) case 1 and (b) case 2.
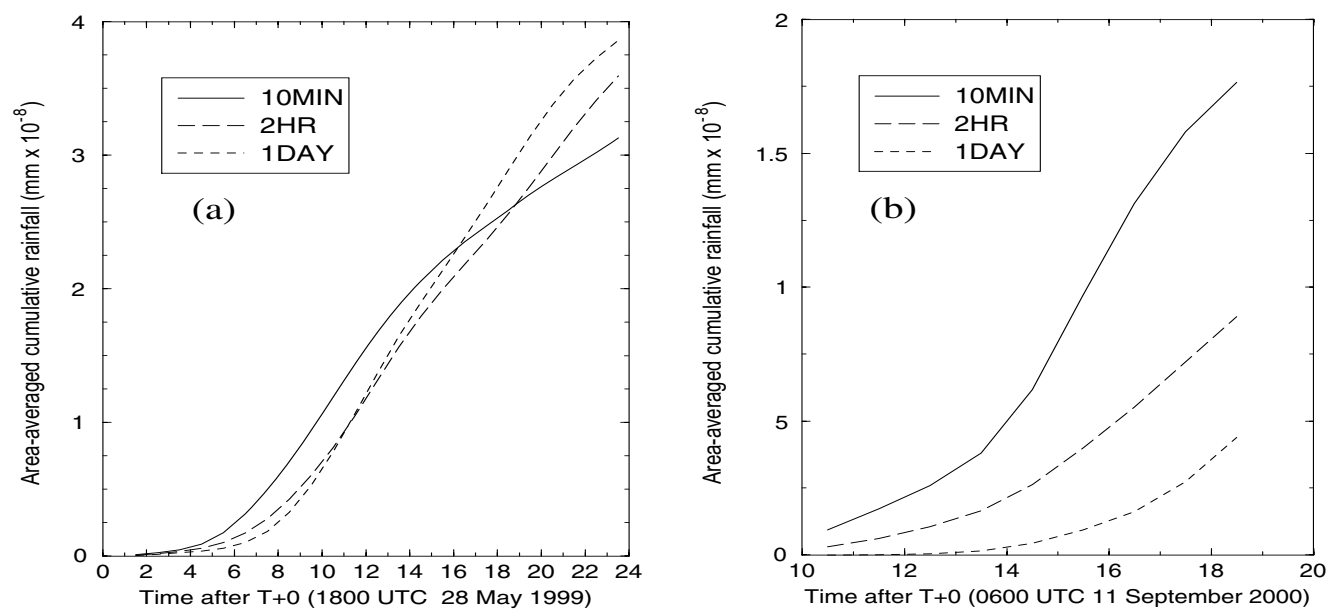

Figure 6. Area-averaged cumulative rainfall for 10MIN, 2HR and 1DAY for (a) case 1 and (b) case 2.
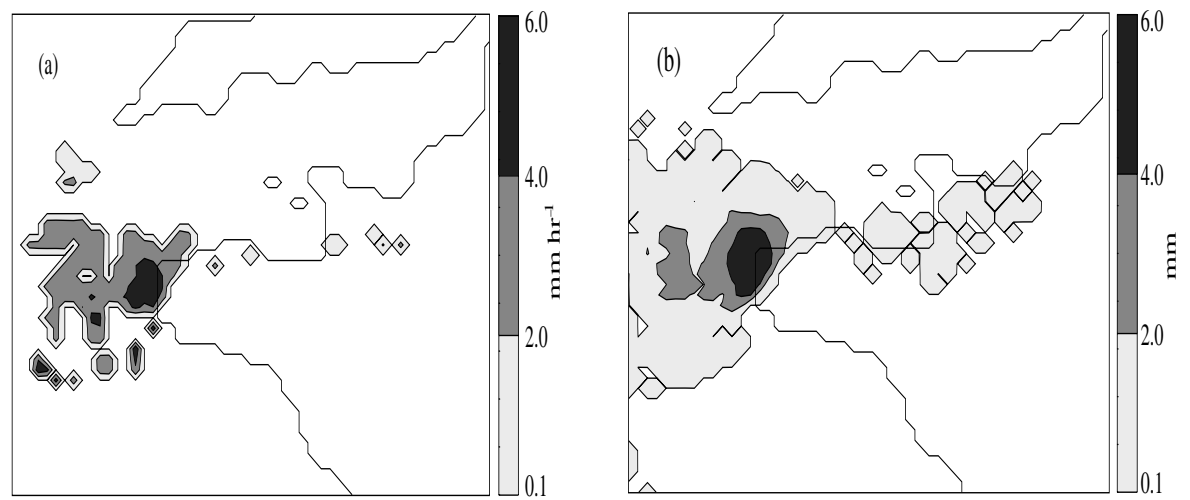

Figure 7. (a) Instantaneous parametrized rain rate at 0000 UTC 29 May $1999\left(\mathrm{~mm} \mathrm{hr}^{-1}\right.$, shaded) and (b) one hour accumulated parametrized rainfall from 0000 UTC 29 May 1999 (mm, shaded) for case 1 experiment 10MIN. The outline of the French and English coasts is superimposed. 

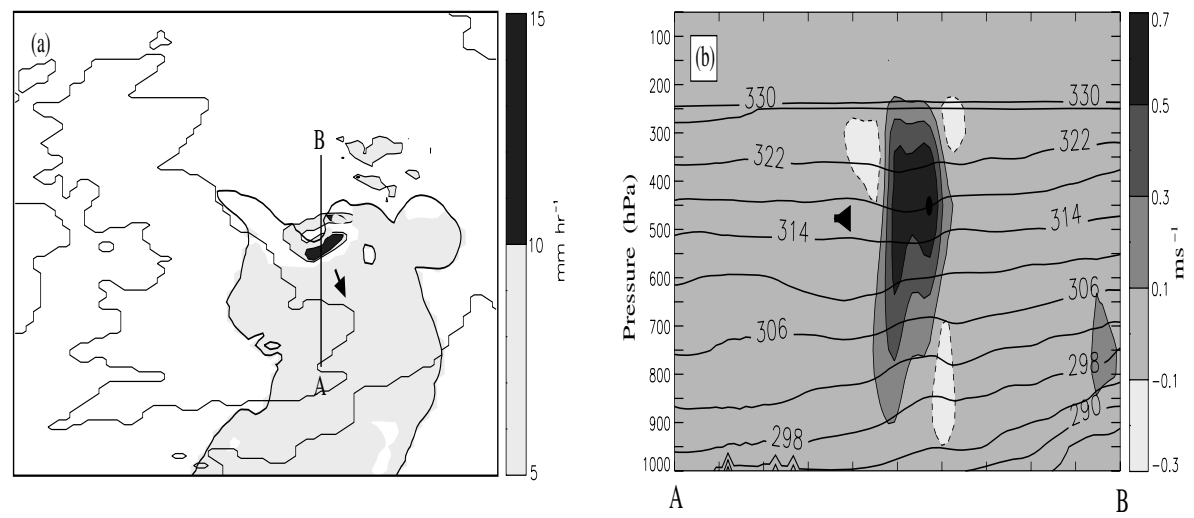

Figure 8. (a) Instantaneous parametrized rain rate $\left(\mathrm{mm} \mathrm{hr}^{-1}\right.$, shaded) at $0000 \mathrm{UTC} 12$ September 2000 for $10 \mathrm{MIN}$. The contour $C A P E=500 \mathrm{~J} \mathrm{~kg}^{-1}$ is indicated by the thick line and $C I N=10 \mathrm{~J} \mathrm{~kg}^{-1}$ within the contour of $C A P E$ is shown by heavy shading. The arrow indicates the direction of propagation of the convective bow. (b) Vertical cross-section of vertical velocity $\left(\mathrm{m} \mathrm{s}^{-1}\right.$, shaded, positive contours are solid and negative contours are dashed) and potential temperature (K, contoured) through the convective bow (line AB in Fig. 8(a)). The arrow indicates the approximate direction of propagation.

Although the instantaneous rain-rate field plotted in Fig. 7(a) is quite noisy, the timeaveraged rain rate over one hour (Fig. 7(b)) is a smooth field of precipitation collocated with the region of $C A P E$ and low $C I N$, as expected of convective equilibrium behaviour.

For case 2 , the scheme behaved very differently, producing bows of convection that did not correspond to any observed features. The bows propagated at $13 \mathrm{~m} \mathrm{~s}^{-1}$ at approximately $90^{\circ}$ to the mid-level environmental flow into the region of high $C A P E$ and high CIN, as shown in Fig. 8(a). The bows increased the cumulative rainfall significantly, as shown earlier in Fig. 6(b). A vertical cross-section through the convective bow (Fig. 8(b)) shows the updraught with anomalously cold air beneath it. Similar features were seen by Roberts (2001), who suggested that they result from a positive feedback mechanism involving a coupling between the convection scheme and the grid-scale dynamics. A cold pool, possibly resulting from prior convection, caused convergence and ascent at its forward edge. This ascent led to the generation of sufficient instability to trigger the convection scheme. The scheme responded instantaneously to this instability and cooled the low levels. This effectively propagated the cold pool forward and triggered the scheme at the next time step, allowing the system to propagate forward and realize the otherwise unavailable reservoir of energy.

\section{(b) Simulations using a two-hour closure timescale}

In the 2HR experiment, the simulations evolve through four stages of partitioning between parametrized and explicit precipitation, as shown for case 1 in Fig. 9. The parametrization scheme triggered at 2100 UTC 28 May 1999, three hours before observed convection (shown an hour later in Fig. 9(a)), over a larger region than observed and collocated with the region of CAPE and low CIN (not shown). Grid-scale precipitation at this time was negligible. Subsequently, explicit precipitation developed (Fig. 9(b)) as part of the large-scale response to the heating and moistening from the parametrization scheme. However, the explicit precipitation did not have convective characteristics as it was weak and relatively uniform in space. The third stage is marked by the emergence of local intense regions of explicit precipitation (Fig. 9(c)), implying the development of explicit convection and suggesting that the convective tendencies 

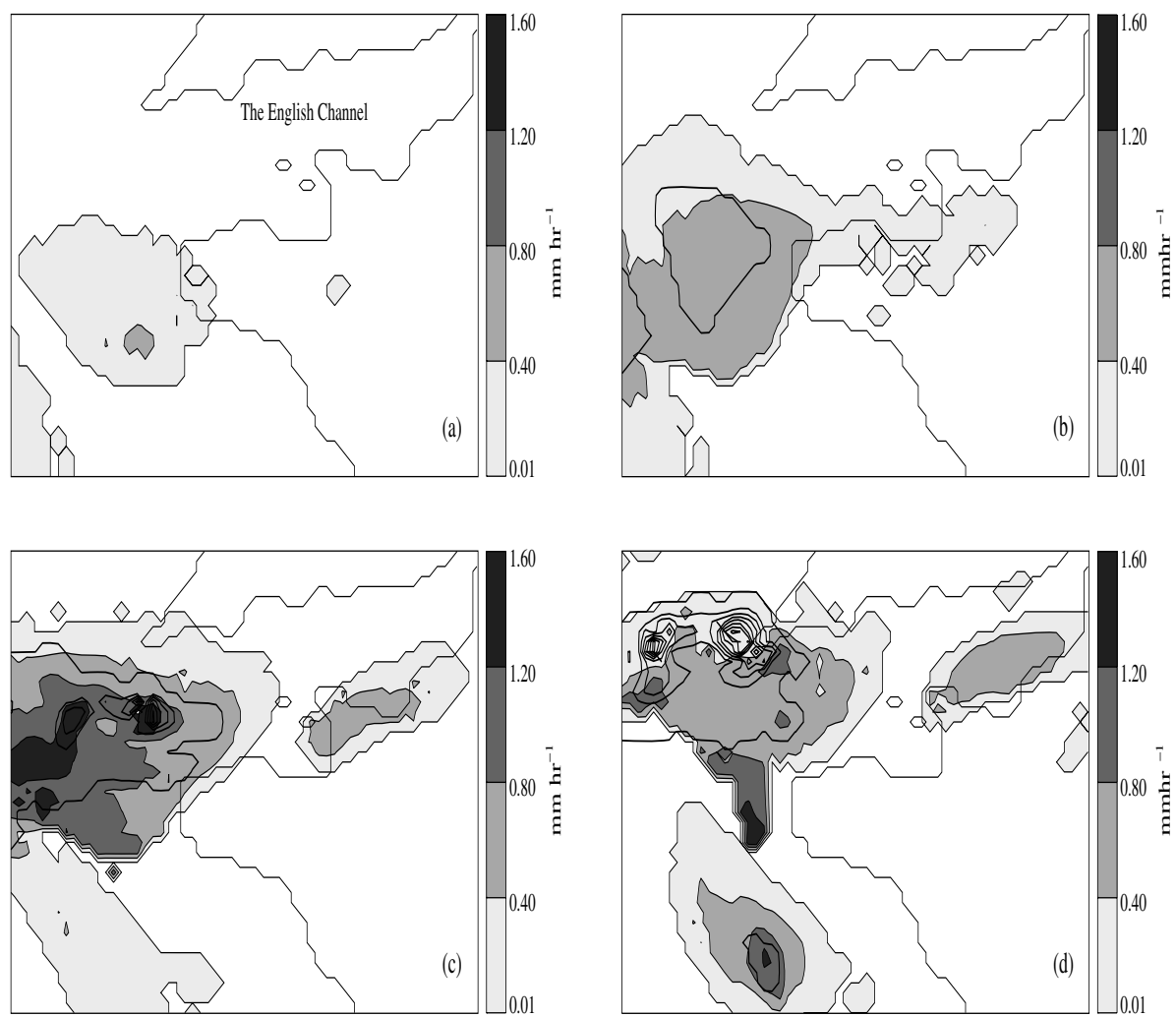

Figure 9. Evolution of parametrized rain rate $\left(\mathrm{mm} \mathrm{hr}^{-1}\right.$, shaded) and explicit rain rate $\left(\mathrm{mm} \mathrm{hr}^{-1}\right.$, thick contours with a contour interval $3.0 \mathrm{~mm} \mathrm{hr}^{-1}$ starting at $0.01 \mathrm{~mm} \mathrm{hr}^{-1}$ ) in $2 \mathrm{HR}$ for case 1. (a) Stage 1: Parametrized convection, 2200 UTC 28 May 1999, (b) Stage 2: Development of explicit precipitation, 0000 UTC 29 May 1999, (c) Stage 3: Simultaneous increase in explicit and parametrized rain rates, 0300 UTC 29 May 1999 and (d) Stage 4: Explicit precipitation dominates locally, 0500 UTC 29 May 1999.

from parametrized convection were too small to achieve equilibrium with the largerscale destabilization. This was followed by a simultaneous strengthening of explicit convection and weakening of parametrized convection that occurred locally within the unstable region after 0500 UTC, as shown in Fig. 9(d). Maximum explicit precipitation rates increased to $20 \mathrm{~mm} \mathrm{hr}^{-1}$ by $0500 \mathrm{UTC}$, but remained only a fifth of those observed.

The model failed to initiate the locally intense convection over the English Channel, observed at 0400 UTC, that developed into the organized MCS over southern England. The CAPE at 0600 UTC was lower over the English Channel than further west, and homogeneous weak parametrized convection within this region (Figs. 9(b), (c) and (d)) was sufficient to suppress explicit convection. Although the model produced intense local regions of precipitation, it failed to produce the squall-line-like propagation that was observed. It is not expected that a model with horizontal grid spacing of $12 \mathrm{~km}$ could resolve such structures (e.g. Weisman et al. 1997).

For case 2, the convective solution evolved through the same stages of partitioning identified for case 1 (not shown). Some parametrized convection penetrated into the region of CAPE and high CIN, as occurred in $10 \mathrm{MIN}$, but it was far weaker and dissipated earlier. 

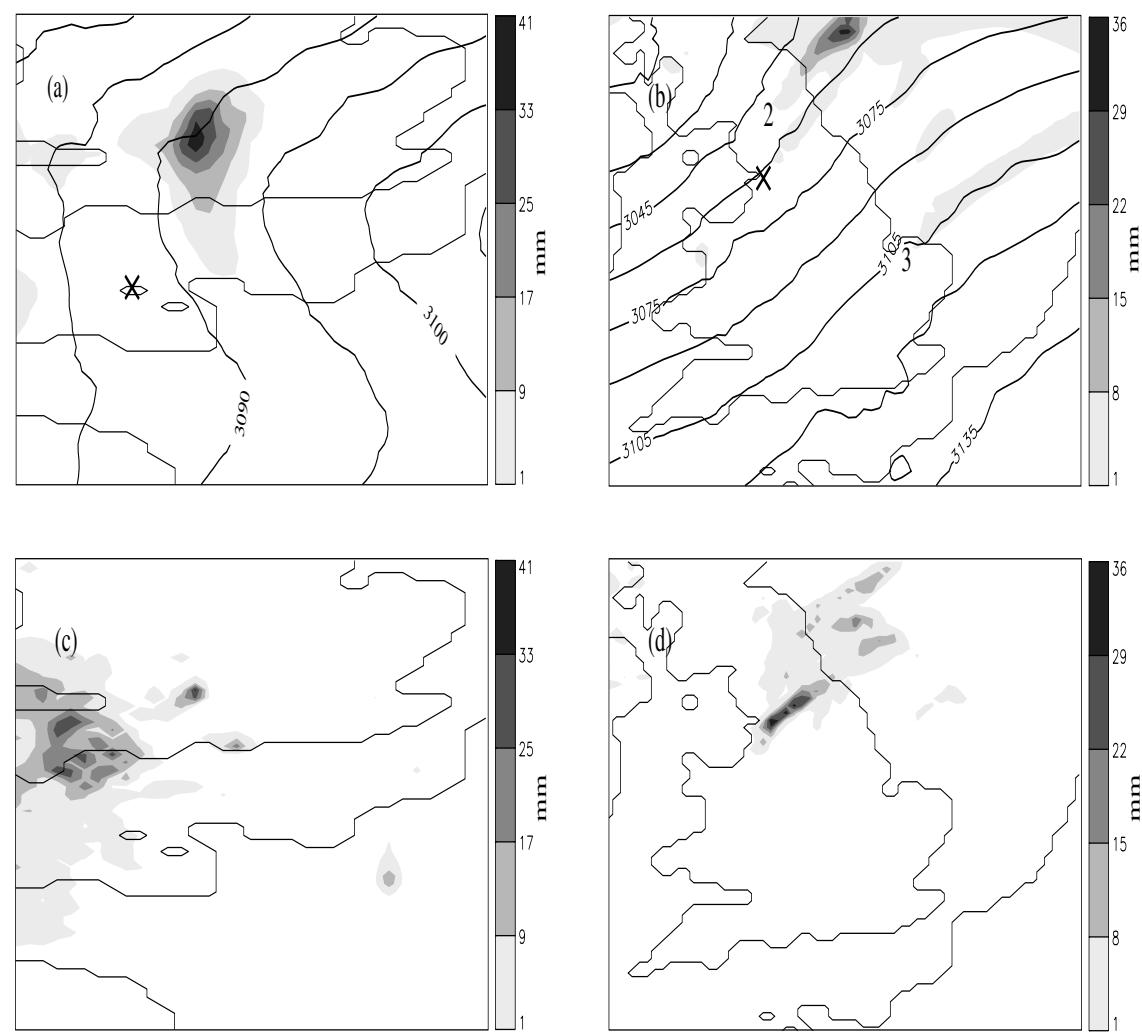

Figure 10. Cumulative rain amount (mm, shaded) for (a) 1DAY case 1 0300-1300 UTC 29 May 1999 and (b) 1DAY case 21800 UTC 11 September to 0100 UTC 12 September 2000, and cumulative rain amounts derived from network radar data interpolated onto the model grid for the same periods for (c) case 1 and (d) case 2 . Model geopotential height at $700 \mathrm{mb}$ in the middle of the accumulation period is contoured at interval $5 \mathrm{~m}$ in (a) and $15 \mathrm{~m}$ (b). The crosses in (a) and (b) mark the observed locations of initiation.

\section{(c) Simulations using a one-day closure timescale}

For both cases, the 1DAY experiment produced a convective response consisting of persistent explicit convective cells. The horizontal scale of the cells was constrained by the horizontal grid spacing of the model and tended to expand with time at a rate controlled by horizontal diffusion (not shown). For case 1, in contrast to 10MIN and $2 \mathrm{HR}$, intense convection was initiated further east over the English Channel, from 0400 UTC, as observed. The explicit cell was triggered over the region of the Cherbourg peninsula and tracked north with the mid-level environmental flow, as shown in Fig. 10(a). The cell generated rain rates that were comparable to those observed and extended to $7 \times 7$ grid lengths by 1100 UTC. The cell was triggered $100 \mathrm{~km}$ east of the location of the observed cell, which is marked by a cross in Fig. 10(a), and shown in quality-controlled network radar data in Fig. 10(c). Over England the mid-level flow in the region of the cell turned to the east and intense convection was advected eastnorth-east across southern England, as observed. Explicit convection further west (not shown) remained over the Irish Sea, where the mid-level southerly flow did not turn to the east at the confluent asymptote, and failed to reproduce the observed squall-line-like propagation. 

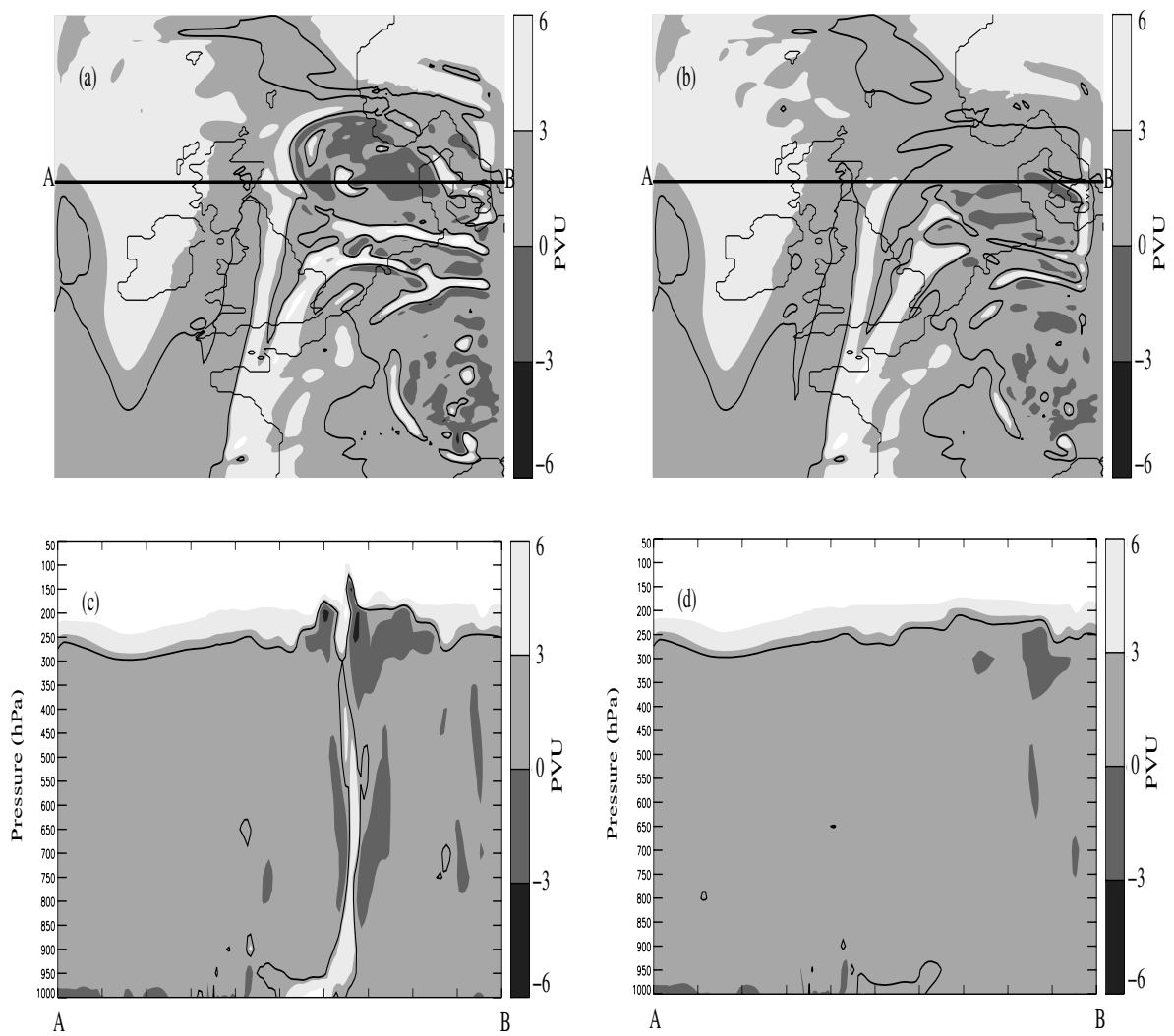

Figure 11. Dry potential vorticity (PVU) at 0600 UTC 12 September 2000, 12 hours after the initial triggering of convection for (a) and (c) 1DAY and (b) and (d) 10MIN: (a) and (b) at $250 \mathrm{mb}$, and (c) and (d) along the vertical cross-section AB. The thick black lines show the 2 PVU contour.

For case 2, three cells tracked parallel to the mid-level environmental flow, as shown in Fig. 10(b). The observed cell tracks shown in Fig. 10(d) also ran parallel to the midlevel environmental flow. The model triggered one explicit cell in the location of the observed initiation and another two hours early, marked by a number 2 in Fig. 10(b), both within the region of CAPE and low CIN over northern England. The model did not capture the relative strength and timing of the convective cells, but did represent the overall history. For the first few hours, maximum model rain rates of $1-5 \mathrm{~mm} \mathrm{hr}^{-1}$ were well below the $45-68 \mathrm{~mm} \mathrm{hr}^{-1}$ observed. Maximum model rain rates increased to $36 \mathrm{~mm} \mathrm{hr}^{-1}$ over the North Sea while those observed fell to, typically, $20 \mathrm{~mm} \mathrm{hr}^{-1}$. The other explicit cell was not observed in nature and was initiated five grid points $(60 \mathrm{~km})$ inland from the coast of central eastern England, marked by the number 3 in Fig. 10(b), within the region of CAPE and high CIN (see Fig. 3(b)). It may have been triggered by an overly intense sea-breeze circulation, a problem not unexpected using a high-resolution hydrostatic model.

\section{RESULTS III: LARGE-SCALE SENSITIVITY TO PARTITIONING}

The large-scale impact of the various treatments of convection can be described succinctly by the resulting distributions of PV. Explicit convection in 1DAY generated a lens-shaped region of negative PV at upper levels, as shown for case 2 in Fig. 11(a). 

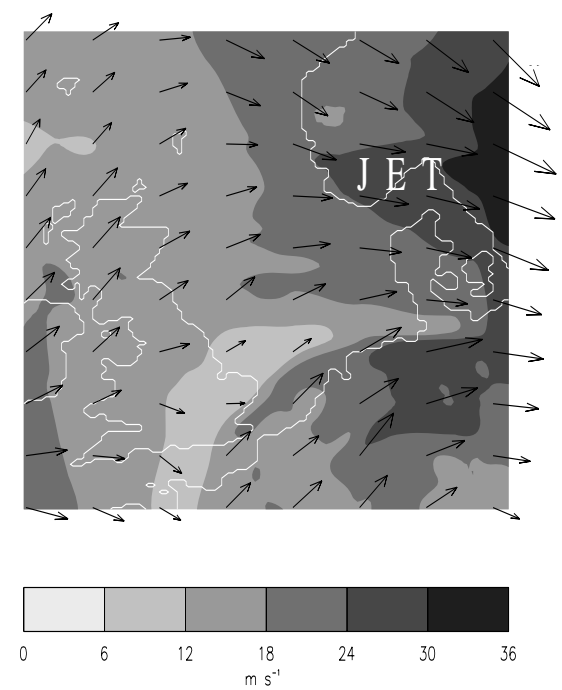

Figure 12. Wind speed (shaded) and wind vectors at $250 \mathrm{mb}$ for the background flow at 0600 UTC 12 September 2000.

Parametrized convection in $10 \mathrm{MIN}$, on the other hand, resulted in a poorly defined region of weaker negative PV at upper levels, as shown in Fig. 11(b). Vertical crosssections of PV through the convecting region, shown in Figs. 11(c) and (d), show the lens of negative PV in 1DAY penetrated above the tropopause level of the local environment. However, convection in 10MIN, had much less of an effect on the height of the tropopause (defined here as the 2 PVU* $^{*}$ surface). Similar PV structures occurred in the experiments for case 1 (not shown). For both cases, the magnitude and distribution of convectively generated PV is sensitive to the partitioning of convection, despite the similar cumulative rainfall (and, therefore, the net latent heating due to convection) to those of the experiments on case 1 .

$\mathrm{PV}$ anomalies are associated with anomalies in the dynamical and thermodynamical fields; in particular, anomalies near the tropopause can be linked to changes in jet strength. The change in the large-scale flow due to convection can be determined by subtracting a background flow. The background flow for case 2, shown in Fig. 12, was determined by performing a simulation with the latent heating due to condensation and freezing set to zero- - thus removing convectively generated PV. For 1DAY, convection increased the background $250 \mathrm{mb}$ jet speed by up to $20 \mathrm{~m} \mathrm{~s}^{-1}$ along the northern edge of the PV lens, as shown in Fig. 13(a), whereas for 10MIN convection increased the $250 \mathrm{mb}$ jet speed by up to $10 \mathrm{~m} \mathrm{~s}^{-1}$, as shown in Fig. 13(b). This confirms that the large-scale dynamical response to convection was sensitive to the partitioning of convection, but raises the question of which representation of convection gave more realistic results.

The thermodynamical model response can be compared with the response of the real atmosphere using radiosonde ascents from the Ekofisk oil platform in the North Sea $\left(56.53^{\circ} \mathrm{N}, 3.22^{\circ} \mathrm{E}\right)$, marked by a cross in Fig. $14(\mathrm{a})$. The radiosonde ascents, shown in Fig. 14(b), provide evidence of a transient tropopause-level thermodynamic modification as the MCS moved over the site. The radiosonde released at 0000 UTC 12 September 2000 ascended through the north-eastern edge of the convectively generated cirrus shield, as shown in Fig. 14(a). A transient warming below the $250 \mathrm{mb}$ tropopause and

* Potential vorticity units. $1 \mathrm{PVU}=10^{-6} \mathrm{~m}^{2} \mathrm{~s}^{-1} \mathrm{~K} \mathrm{~kg}^{-1}$. 

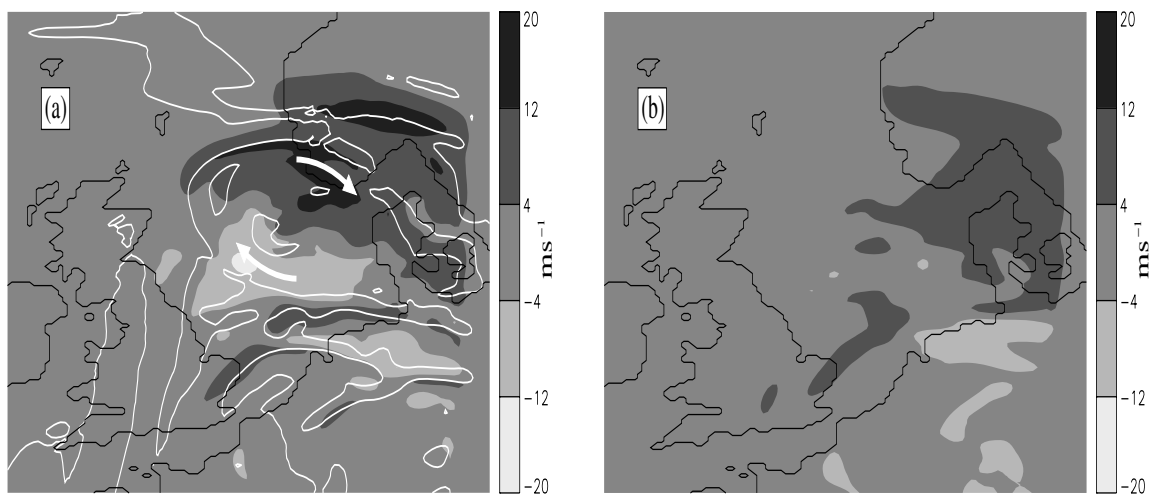

Figure 13. The change in wind speed (shaded) at $250 \mathrm{mb}$ due to convection in (a) 1DAY and (b) 10MIN at 0600 UTC 12 September 2000, 12 hours after the initial triggering. Overplotted in (a) is a white line indicating the 2 PVU contour at $250 \mathrm{mb}$, showing the lens-shaped region of convectively generated PV. The arrows in (a) indicate anticyclonic rotation. The boundary conditions were generated from the global model with moist dynamics and the convection scheme with a two-hour closure timescale. As a result, the difference fields tend to zero at the boundary.
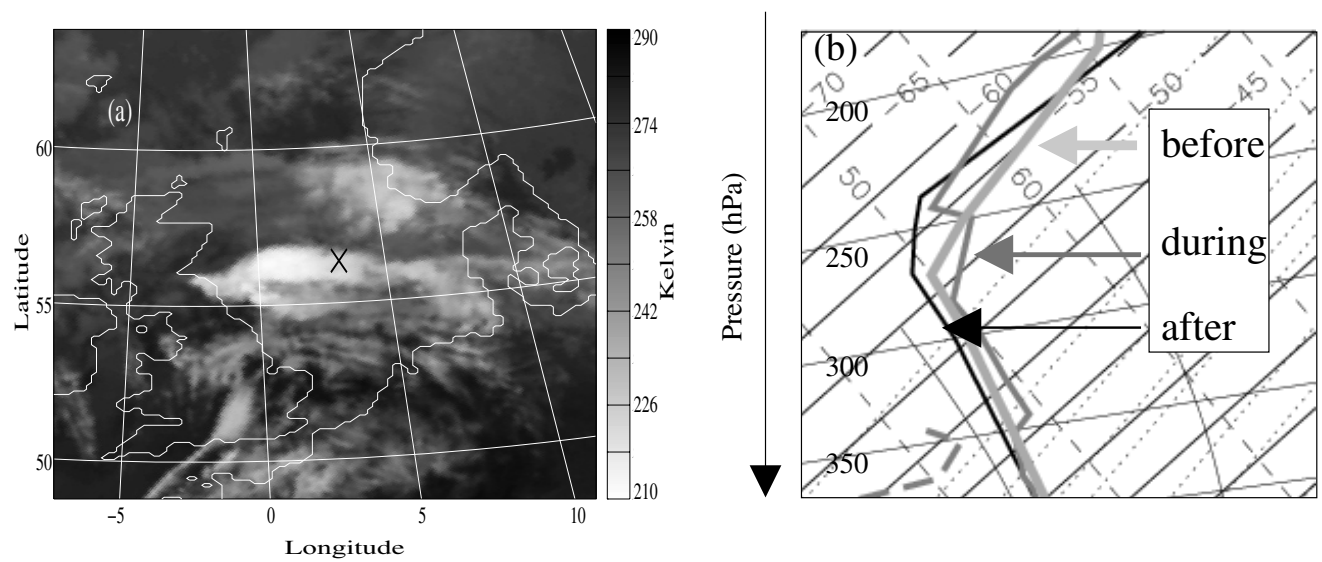

Figure 14. (a) Meteosat IR imagery at 0100 UTC 12 September 2000. The location of the Ekofisk oil platform is marked by a cross. (b) Observed temperature (solid) and dew-point temperature (dashed) profiles at the Ekofisk oil platform, 12 hours before (light grey), during (dark grey) and 24 hours after (black) the MCS.

cooling above $250 \mathrm{mb}$ is consistent with an injection of mass into isentropic layers about the tropopause via deep convection, and is a signature of reduced PV. For 1DAY, the transient cooling above $225 \mathrm{mb}$ and transient warming below $250 \mathrm{mb}$, shown in Fig. 15(a), are consistent with the observed modification. There is some transient cooling above $225 \mathrm{mb}$ in $10 \mathrm{MIN}$, but there is no evidence of any warming below, as shown in Fig. 15(b). For $10 \mathrm{MIN}$, the vertical profile due to convection was a tropospheric deep layer of saturated adiabatic lapse rate, consistent with removal of CAPE on a fast timescale. The structure at the tropopause associated with an injection of low-PV air was not reproduced. On the other hand, explicit convection in 1DAY resulted in a large-scale upper-level modification closer to observations. 

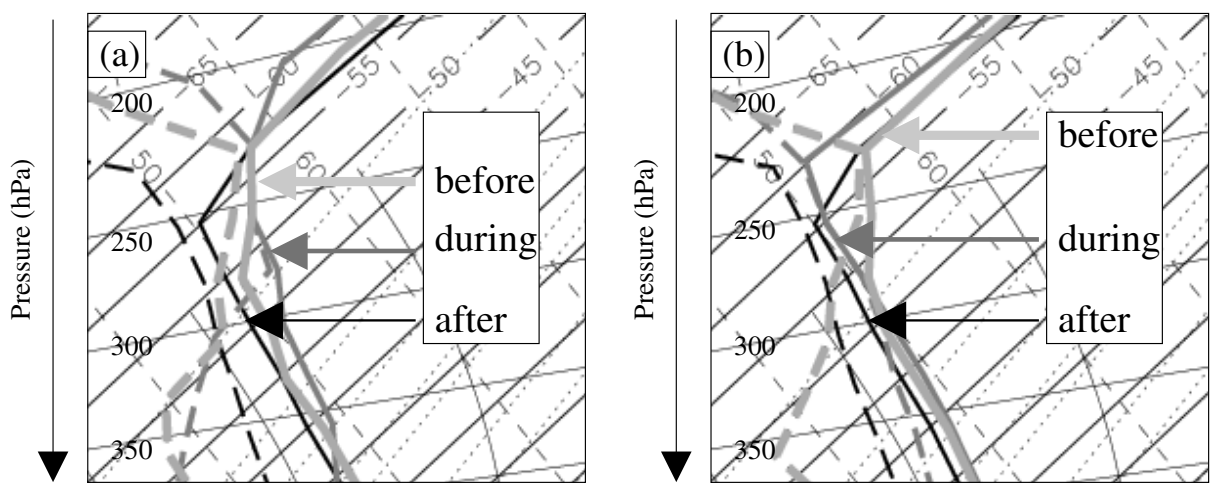

Figure 15. Model temperature (solid) and dew-point temperature (dashed) profiles at Ekofisk 12 hours before convection (light grey), at Ekofisk during convection (dark grey) and downstream from convection (black) for (a) 1 DAY and (b) $10 \mathrm{MIN}$.

\section{SUMMARY AND DISCUSSION}

The behaviour of parametrized and explicit convection in a mesoscale model has been examined in simulations of two mesoscale convective systems over the UK. The model has an explicit (grid-scale) precipitation scheme, and a convective parametrization that removes $C A P E$ over a prescribed timescale, and is thus appropriate for conditions where the convection is in equilibrium with the large-scale forcing. The aim of the study was to consider whether the presence or absence of convective equilibrium in a particular meteorological situation would be a determining factor in the behaviour of the two treatments of convection. To this end, case 1 was chosen to have a large region of conditional instability (CAPE) with relatively little inhibition $(C I N)$, so that the ensemble of convective clouds should have space and time to reach equilibrium with the large-scale forcing. In contrast, case 2 had only a small region where instability was combined with little inhibition, making equilibrium unlikely. In addition, the differences in the time evolution of area-average CAPE and the differences in the time evolution and magnitude of the timescale of convective adjustment between the cases are consistent with the hypothesis of equilibrium for case 1 and non-equilibrium for case 2. For each case, three experiments were performed, varying the timescale over which the convection scheme removes instability through ten minutes, two hours and one day, leading to purely parametrized convection, mixed parametrized and explicit convection, and purely explicit convection, respectively.

The first question posed in the introduction was whether the equilibrium-based cumulus parametrization would behave well when equilibrium was expected to occur in the atmosphere, and indeed this appears to happen. In case 1 the parametrization produced a region of rainfall that coincided with the forcing region. The total precipitation over this region should be determined by the forcing, and indeed it was found to be independent of the partitioning between parametrized and explicit rainfall. With the convection scheme turned off, the explicit precipitation also behaved well, at least to the extent that it gave the same value for the total rainfall. The precipitation was concentrated in intense localized regions, with a scale presumably determined by the model diffusion and, although the squall-line-like structure that occurred late in the day was not reproduced, the precipitation features did follow the mid-level steering flow, as observed. The large-scale response to the convection, as indicated by production of low PV at upper levels, was different for explicit and parametrized convection and 
for case 2, where data were available, the explicit convection produced more realistic results. The answer to the second question, whether an explicit representation of convection would behave well when convective equilibrium is expected, would also appear to be 'yes', although features that could not be resolved by the model grid were of course not simulated.

The final question raised in the introduction was whether either treatment of convection would provide useful information in a situation where equilibrium was not expected (case 2). This was emphatically not the case for the parametrized convection which produced excessive rainfall in the form of bow structures that were not observed in the real atmosphere. The explicit treatment showed similar behaviour to that seen in the equilibrium case, with perhaps even some skill in the location of the convection. However, the total rainfall was quite sensitive to the treatment of convection.

In these two cases, the presence or absence of convective equilibrium seems to be a significant factor in determining the behaviour of convection, whether parametrized or explicit. It is important to stress that equilibrium is a physical balance based on scale separation between cloud and forcing scales and does not depend on model resolution. In the equilibrium case 1, for example, the parametrization performs well since the physical forcing scale is large, even though the model grid scale is not. In general, the high resolution would make it possible for the model to simulate a forcing that varies on small scales, but this did not occur in case 1 .

While two cases are not sufficient to characterize all the factors that will affect model convection, it seems reasonable to conclude that the presence or absence of equilibrium should generally be important. Other results of the simulations here, though interesting, may be specific to the cases and parametrization scheme used in this study. Despite the fact that the model at $12 \mathrm{~km}$ grid spacing employed here is, by no stretch of the imagination, cloud-resolving, there seemed to be little disadvantage to running the model without a convection scheme in these two cases. Although the precipitation is characterized by rather unrealistic localized updraught regions, they produce the appropriate total rainfall in the equilibrium case, show some skill in location for the nonequilibrium case, and realistically follow the mid-level steering flow. Additionally, the upper-level response to the convection appears more realistic than for the parametrized convection. This behaviour seems to be unrelated to convective equilibrium (which would suggest the response should be independent of convective timescale for case 1, as was true of precipitation), and demonstrates that even in situations where a convective parametrization would be valid it is important to have a correct parametrization.

\section{ACKNOWLEDGEMENTS}

This work was supported by Met Office grant PB/b/2987 and Natural Environment Research Council grant GT04/99/AS/229.

\section{REFERENCES}

Arakawa, A. and Schubert, W. H.

Brandes, E. A.

Cohen, B. G. and Craig, G. C.
1974

1990

2006
Interaction of a cumulus cloud ensemble with the large-scale environment, Part I. J. Atmos. Sci., 31, 674-701

Evolution and structure of the 6-7 May 1985 mesoscale convective system and associated vortex. Mon. Weather Rev., 118, 109-127

Fluctuations in an equilibrium convective ensemble. Part II: Numerical experiments. J. Atmos. Sci., 63, (in press) 
Craig, G. C. and Cohen, B. G.

2006

Cullen, M. J. P.

Dudhia, J.

1993

1989

Edwards, J. M. and Slingo, A.

1996

Emanuel, K. A.

1994

Gallus, W. A.

1999

Gregory, D. and Rowntree, P.

1990

Houze, R. A.

1982

Johnson, R. H.

1984

Kain, J. S. and Fritsch, J. M.

1998

Kato, T. and Saito, K.

1995

Kuo, Y. and Reed, R. J.

1988

Kuo, Y., Bresch, J. F., Cheng, M.-D., Kain, J. S., Parsons, D. B., Tao, W.-K. and Zhang, D.-L.

Liu, C., Moncrieff, M. W. and Grabowski, W. W.

Lock, A. P., Brown, A. R. Bush, M. R., Martin, G. M. and Smith, R. N. B

Lorenc, A. C., Ballard, S., Bell, S., Ingelby, N., Andrews, P., Barker, D., Bray, J., Clayton, A., Dalby, T., Li, D., Payne, T. and Saunders, F.

Marshall, J. S. and Palmer, W. M. K.

Molinari, J. and Dudek, M.

Morris, R. M.

1986

Roberts, N.

Sachidananda, M. and Zrinć, D. S.

1986

Schwartz, B. E., Chappell, C. F., Togstad, W. E. and

Zhong, X.-P.

Spencer, P. L. and Stensrud, D. J.

Stensrud, D. J.

2001

2000

2000
Fluctuations in an equilibrium convective ensemble. Part I: Theoretical basis. J. Atmos. Sci., 63, (in press)

The unified forecast/climate model. Meteorol. Mag., 122, 81-94

Numerical study of convection observed during the winter monsoon experiment using a mesoscale, two-dimensional model. J. Atmos. Sci., 46, 3077-3107

Studies with a flexible new radiation code. I: Choosing a configuration for a large-scale model. Q. J. R. Meteorol. Soc., 122, 689-719

Atmospheric convection, Oxford University Press, New York

Eta simulations of three extreme precipitation events: Impact of resolution and choice of convective parameterization. Weather and Forecasting, 14, 405-426

A mass-flux convection scheme with representation of cloud ensemble characteristics and stability-dependent closure. Mon. Weather Rev., 118, 1483-1506

Cloud clusters and large-scale vertical motions in the tropics. J. Meteorol. Soc. Jpn., 60, 396-410

Partitioning tropical heat and moisture budgets into cumulus and mesoscale components: Implications for cumulus parameterization. Mon. Weather Rev., 112, 1590-1601

Multiscale convective overturning in mesoscale convective systems: Reconciling observations, simulations and theory. Mon. Weather Rev., 126, 2254-2273

Hydrostatic and non-hydrostatic simulations of moist convection: Applicability of the hydrostatic approximation to a highresolution model. J. Meteorol. Soc. Jpn., 73, 59-77

Numerical simulation of an explosively deepening cyclone in the eastern Pacific Mon. Weather Rev., 116, 2081-2105

1997 Summary of a mini workshop on cumulus parameterization for mesoscale models. Bull. Amer. Meteorol. Soc., 78, 475-491

Explicit and parameterized realisations of convective cloud systems in TOGA COARE. Mon. Weather Rev., 129, 1689-1704

A new boundary layer mixing scheme. Part 1: Scheme description and single-column model tests. Mon. Weather Rev., 128, 3187-3199

The Met Office global three-dimensional variational data assimilation scheme. Q. J. R. Meteorol. Soc., 126, 2991-3012

The distribution of raindrops with size. J. Meteorol., 5, 165-166

1986 Implicit versus explicit convective heating in numerical weather prediction models. Mon. Weather Rev., 114, 1822-1831

1992 Parameterization of convective precipitation in mesoscale numerical models: A critical review. Mon. Weather Rev., 120, 326-344

The Spanish plume-testing the forecaster's nerve. Meteorol. Mag., 115, 349-357

'Results from simulations of an organised convective event using the New Dynamics at 12, 4 and $2 \mathrm{~km}$ resolution'. Tech. Report, 126, Joint Centre for Mesoscale Meteorology, University of Reading, PO Box 243, Reading, Berkshire RG6 2BB, UK

Differential propagation phase shift and rainfall rate estimation. Radio Sci., 21, 235-247

1990 The Minneapolis flash flood: Meteorological analysis and operational response. Weather and Forecasting, 5, 3-21

1998 Simulating flash flood events: Importance of the subgrid representation of convection. Mon. Weather Rev., 126, 2884-2912

2001 Using short-range ensemble forecasts for predicting severe weather events. Atmos. Res., 56, 3-17 
Stensrud, D. J. and Fritsch, J. M.

1993

Stensrud, D. J., Manikin, G. S., Rogers, E. and Mitchell, K. E. Stensrud, D. J., Bao, J.-W. and Warner, T. T.

Wang, W. and Seaman, N. L.

Weisman, M., Skamarock, W. and Klemp, J.

Wilson, D. R. and Ballard, S. P.

Zhang, D.-L., Hsie, E.-Y. and Moncrieff, M. W.
Mesoscale convective systems in weakly forced large-scale environments. Part I: Observations. Mon. Weather Rev., 121, 3326-3344

1994 Mesoscale convective systems in weakly forced large-scale environments. Part II: Generation of a mesoscale initial condition. Mon. Weather Rev., 122, 2068-2083

1999 Importance of cold pools to NCEP mesoscale Eta model forecasts. Weather and Forecasting, 14, 650-670

2000 Using initial condition and model physics perturbations in short-range ensemble simulations of mesoscale convective systems. Mon. Weather Rev., 128, 2077-2107

1997 A comparison study of convective parameterization schemes in a mesoscale model. Mon. Weather Rev., 125, 252-278

1997 The resolution dependence of explicitly modeled convective systems. Mon. Weather Rev., 125, 527-548

1999 A microphysically based precipitation scheme for the UK Meteorological Office Unified Model. Q. J. R. Meteorol. Soc., 125, 1607-1636

1988 A comparison of explicit and implicit predictions of convective and stratiform precipitating weather systems with a meso- $\beta$ scale numerical model. Q. J. R. Meteorol. Soc., 114, 31-60 